\title{
LA METAMORFOSIS DE LA CIUDAD LITERARIA: TRADICIÓN Y RUPTURA EN LA CIUDAD MUERTA DE ABRAHAM VALDELOMAR
}

\author{
$M^{a}$ Elena Martínez-Acacio Alonso \\ Universidad de Alicante \\ elena.martinezacacio@gmail.com
}

RESUMEN: Con su novela corta La ciudad muerta (1911), el escritor peruano Abraham Valdelomar (1888-1919) rompe con la tradición evocadora de Lima como Arcadia Colonial. El autor se sitúa en la estela del modernismo latinoamericano y reescribe el tópico europeo de "la ciudad muerta", configurando así una imagen bohemia y decadente de la capital peruana inédita hasta el momento. El espacio urbano se tiñe además de un ambiente inquietante que entra en el terreno de lo fantástico, y las coordenadas espacio-temporales se distorsionan hasta descomponerse: ciudad moderna y ciudad colonial se funden en un universo fantasmagórico y misterioso, como respuesta simbólica a las transformaciones sufridas por la ciudad con la llegada la modernidad.

PALABRAS CLAVE: Abraham Valdelomar, literatura y espacio urbano, literatura fantástica.

ABSTRACT: In his novella La ciudad muerta (1991), the Peruvian writer, Abraham Valdelomar (1888-1919), breaks with the traditional perception of Lima as a "Colonial Arcadia". The author follows the modernist Latin American tradition and rewrites the European topic of the "dead city", thus creating an innovative bohemian and decaying image of the Peruvian capital. Moreover, the urban space turns into an uncanny territory that enters a world of fantasy. The spatial and temporal barriers are distorted until the modern city and the colonial city merge in a phantasmagorical and mysterious universe which stands as a symbolic answer to the transformations that Lima suffered upon the arrival of modernity.

KEYWORDS: Abraham Valdelomar, literature and the city, fantastic literature

El escritor peruano Abraham Valdelomar (1888-1919) escribió tan solo dos novelas: La ciudad muerta y La ciudad de los tísicos. Se trata de dos obras de juventud herederas directas del modernismo, en las que podemos apreciar, además, la influencia de la literatura finisecular europea, especialmente la francesa. Pese a la marcada influencia de las más novedosas corrientes tanto hispanoamericanas como europeas, en estas novelas Valdelomar vuelve su mirada al Perú, puesto que sitúa ambos textos en la Lima de principios del siglo XX. En este artículo me ceñiré a la primera de estas novelas, La ciudad muerta, ${ }^{1}$ A través del análisis observaremos cómo el autor se instala en la tradición de la literatura urbana peruana, para cancelarla y revertirla a través de un tratamiento novedoso de los factores espacio y tiempo, mediante la técnica modernista.

\section{Lima como Arcadia Colonial en la literatura peruana}

Para comprender plenamente esta novela de Valdelomar es necesario remontarnos al momento de la independencia del Perú, con objeto de observar la presencia de Lima

\footnotetext{
${ }^{1}$ La ciudad muerta fue publicada por entregas, en forma de folletín en cinco números de la revista Ilustración peruana (números 80, 81, 82, 83 y 85), entre el 12 de abril y el 17 de mayo de 1911.
} 
en la literatura nacional. Para trazar este recorrido ha resultado imprescindible atender al estudio de Eva Valero, Lima en la tradición literaria del Perú. De la leyenda urbana a la disolución del mito.

Como explica Jorge Basadre en su ensayo La multitud, la ciudad y el campo, el proceso de la independencia peruana careció del empuje y la energía que manifestaron otras áreas del continente. Como es bien sabido, Perú permaneció como último bastión imperial español y su liberación sólo se produjo gracias a la intervención de tropas vecinas, primero con San Martín en 1821 y, ya de forma definitiva, con Bolívar en 1824 (Basadre, 1980: 132-144). Eva Valero ha calificado el proceso como "emancipación sobrevenida" (2010: 255), en tanto que la emancipación peruana aparece como un efecto colateral del resto de procesos independentistas del continente más que como fruto de un deseo genuino de liberación nacional por parte de los peruanos:

la independencia es, por tanto, un acontecimiento político, más que económico o social [...]. La nación recién construida no modifica sus bases. Al contrario, sus cimientos más sólidos parecen inamovibles y se avecina la penetración de los nuevos mercados europeos, británicos y franceses fundamentalmente, que agravarán más la situación hasta el momento del desastre de 1879, cuando estalla la guerra del Pacífico entre Chile y Perú. (Valero Juan 2003: 57)

Y en este contexto, como señala la autora, "la imagen de la ciudad fue la prueba más contundente de la pervivencia del antiguo status colonial. Puesto que el fervor revolucionario se disipó tras la guerra, Lima recobró su idiosincrasia de apacible Ciudad de los Reyes y con ella sus costumbres coloniales" (Valero Juan, 2003: 58).

En un primer momento, inmediatamente después de lograda la independencia, los escritores fijaron su atención en el presente y retrataron la vida cotidiana de la ciudad, en un intento de localizar los rasgos propios de la identidad peruana. En este sentido "el costumbrismo se configuró como discurso narrativo para ese intento de definición nacional que se planteaba como problema fundamental a principios de siglo" (Valero Juan, 2010: 258).

Ahora bien, a lo largo del siglo observamos una evolución, lógica si tenemos en cuenta el devenir de la historia. Dicha evolución, simplificadamente, se reduce al tránsito desde una tendencia que podríamos calificar como presentista, propia del momento emancipador y extensible hasta mediados del siglo XIX, a una tendencia pasatista, que nace en las Tradiciones de Palma como respuesta de una sociedad aletargada y anclada en el recuerdo de las grandezas de la Lima virreinal. La promesa de la vida peruana simbolizada en la Independencia había sucumbido, pues el cambio real en la sociedad no se produjo. Por ello la utopía regresa desde el futuro para anclarse en un pasado en el que "la Lima que se va" se configura como Paraíso perdido. (Valero Juan, 2003: 59)

En efecto, en las Tradiciones de Ricardo Palma se plasma esta recuperación del pasado colonial donde el autor "construye la ciudad mítica de la colonia, inaugurando un discurso evocativo cuyas reminiscencias todavía se sentirán a mediados del siglo XX" (Valero Juan, 2004: 130). Sin embargo, esta impasible vida republicana se vio sacudida a finales del siglo XIX a causa de la Guerra del Pacífico, ${ }^{2}$ que supuso una drástica

\footnotetext{
${ }^{2}$ La Guerra del Pacífico (1879-1883) enfrentó a Perú y Bolivia contra Chile. El desencadenante del conflicto fue de tipo económico, a raíz del choque de intereses entre Bolivia y Chile por la explotación del salitre en la región de Atacama. Al estallar el conflicto armado, Perú se vio obligado a apoyar a Bolivia, con quien había firmado un tratado secreto de alianza en 1873. El conflicto se desarrolló principalmente en suelo peruano, demostrando Chile una total superioridad militar. Tras las batallas de Tacna (mayo de 1880) y Arica (junio de 1880) los chilenos desembarcaron cerca de Lima, llegando a tomar la capital en
} 
interrupción de la vida nacional y tuvo consecuencias morales de gran importancia ya que, más allá de las pérdidas económicas o territoriales, supuso la constatación de que el Perú había dejado de ocupar la posición predominante que ostentara durante el periodo virreinal en el sur del continente americano. Durante el conflicto, la capital peruana permaneció ocupada por los chilenos por más de dos años:

Lima enmudeció, absorta como estaba en la contemplación dramática de la destrucción de monumentos como la Biblioteca Nacional. [...] Ante este panorama se abren dos caminos en la historia de las letras y la cultura: el primero, abanderado por Manuel González Prada, supone el primer grito de protesta que impulsa el nacimiento de una literatura novedosa, la que opta por el realismo para referir las confrontaciones entre el campo y la ciudad; el segundo camino encauza la opción pasatista e idealizadora de la ciudad colonial. (Valero Juan, 2003: 114)

Esta visión pasatista enlaza directamente con las Tradiciones de Palma, si bien nos hacemos eco aquí de la siguiente matización:

La literatura de Ricardo Palma es la respuesta al momento independentista, pues el interés por las costumbres se encuentra ligado fundamentalmente a la necesidad de definir la nacionalidad, de afirmar la identidad colectiva, y la predilección por el pasado responde tanto a los postulados de la corriente romántica como a la urgencia por recuperar la conciencia histórica tras el desconcierto reinante en las primeras décadas de la emancipación. Sin embargo, de las Tradiciones surge, irremediablemente, el espejismo de la Colonia, que alimentaría la literatura de la generación posterior a la guerra del Pacífico. Tras la derrota que arruina el país, el espejismo del pasado se acrecienta, y lo que había sido en Palma recuperación vivificante y asimilación de la historia, se convierte ahora en mitificación de un pasado idílico que nunca existió. (Valero Juan, 2003: 129)

Se configura así, tras la Guerra del Pacífico, "el tema de la vieja Lima como Arcadia Colonial" (Valero Juan, 2003: 127) en la obra de los autores de la generación del novecientos que, tras el desastre de la guerra, recrean en sus obras, con tono nostálgico y melancólico, esa Lima del pasado que, tras los acontecimientos recientes de la historia peruana, está ya dejando de existir. La obra más representativa de esta tradición mitificadora de Lima como Arcadia Colonial es Una Lima que se va (1921) de José Gálvez donde, a través de la reconstrucción de los tipos y costumbres del pasado, "emerge una imagen bucólica de la antigua urbe colonial [...] donde la paz y la prosperidad presidían la sosegada vida de los limeños" (Valero Juan, 2003: 131), que contrastaba con la decadente Lima del momento presente, que sucumbía lentamente a los avances del progreso. Otros autores de la misma generación retrataron en sus obras esta misma imagen idílica y nostalgia de Lima; entre ellos destacan los cronistas Ezequiel Balarezo Pinillos (Gastón Roger) y Enrique A. Carrillo (Cabotín), con colecciones de crónicas como La ciudad evocadora (1921) del primero, y Viendo pasar las cosas (1915) del segundo. También en la obra de Ventura García Calderón pueden encontrarse ecos del discurso de Gálvez en su obra Vale un Perú (1939) donde "enaltece y mitifica la antigüedad de la nación desvanecida ante el progreso" (Valero Juan, 2003: 143).

enero de 1881. Tras resistir durante un tiempo en el norte y en la sierra, el presidente provisorio Miguel Iglesias convocó un congreso en Cajamarca que se pronunció a favor de la paz inmediata. El 20 de octubre de 1883 se firmó el Tratado de Ancón, que puso fin a la guerra y tuvo consecuencias nefastas para la economía peruana, ya que en él se estipulaba que Perú debía ceder perpetuamente a Chile la provincia de Tarapacá, y las de Tacna y Arica por un plazo de diez años, al cabo de los cuales debía celebrarse un plebiscito para decidir su nacionalidad definitiva. 
Valdelomar es coetáneo de esta generación que, tras la guerra, inaugura la tradición evocativa de Lima como Arcadia Colonial. En La ciudad muerta Valdelomar evoca también el pasado colonial de la ciudad, situándose así en las coordenadas de esa recuperación pasatista de Lima que hemos trazado. No obstante, en esta novela se manifiesta un claro deseo de originalidad: Valdelomar toma esa tradición y la reescribe de manera innovadora, jugando con los conceptos de espacio y tiempo dentro de la obra y uniendo la evocación colonial con algunos tópicos y formas literarias de la literatura modernista hispanoamericana y también de la literatura finisecular europea.

Hemos de tener en cuenta demás que, como es bien sabido, durante el siglo XIX los efectos de la revolución industrial conllevaron la modificación de los escenarios urbanos europeos $\mathrm{y}$, a partir de las últimas décadas del siglo, también las ciudades latinoamericanas se vieron afectadas por esta oleada modernizadora. La literatura finisecular hispanoamericana, al igual que la europea, se hizo eco de todos estos cambios en el entorno urbano:

La renovación arquitectónica de la modernidad -vinculada estilísticamente a lo que conocemos como Modernismo- está presente en muchas ciudades: desde Buenos Aires a Caracas, Montevideo, Valparaíso, la ciudad de México, o tantas otras urbes de América y tiene una impronta finisecular que, en su eclecticismo, su falta de homogeneidad urbana y de edificios singulares es parte de un sentido de renovación que mantuvo, como se daba en la cultura global, contradicciones profundas entre el pasado y el futuro en un presente que no acababa por determinarse. (Rovira, 2005: 138)

Frente a estos cambios, que en el caso de Lima se conjugaban con el lastre de la guerra, reaccionaron, como decíamos antes, los escritores novecentistas. Valdelomar percibió también estos cambios y las contradicciones que ellos entrañaban, como demuestran sus palabras en una entrevista que concedió al diario La Reforma de Trujillo. Al preguntar el entrevistador si Valdelomar consideraba que Trujillo conservaba todavía su sello colonial, este responde: “¿Quién puede dudarlo? Y esto, precisamente, constituye su principal atractivo. Está muy bien que la ciudad se modernice y adquiera todos los elementos del más exquisito confort, pero conservando y respetando su carácter antiguo, caballeresco, legendario y noble" (S/A, 1996: 138). Valdelomar resuelve este conflicto en su novela combinando tradición y modernidad, es decir, combinando la visión arcádica de la Lima colonial con la visión plena de decadentismo y misterio que caracteriza la urbe moderna.

\section{La ciudad muerta: de la Arcadia Colonial a la ciudad decadente moderna}

La novela La ciudad muerta. Por qué no me casé con Francinette se configura como una larga carta que el protagonista y narrador de la historia dirige a su prometida, una joven francesa llamada Francinette, a la que ha abandonado. La carta es la explicación de los motivos de este abandono. Ocho días antes de la boda, Francinette había explicado a su novio el motivo de su viaje a América: originalmente la joven había acudido al continente en busca de su anterior prometido, el escritor francés Henri D'Herauville, quien había partido de viaje a América y del cual había dejado de tener noticias. Ante esta confesión, el novio se embarca y deja a su prometida. Una vez embarcado, le dirige una carta en la cual le explica que él conoció y fue testigo de la muerte de Henri.

El narrador comienza su historia en la ciudad denominada en el texto como C', ,, en la cual él ejercía de médico que recibía los barcos que llegaban al puerto. En el buque Jeroboam llega Henri D'Herauville y rápidamente nace la amistad entre los dos 
hombres. El francés llegaba a la ciudad deseoso de conocer las ruinas coloniales situadas al pasar un cerro detrás de la ciudad moderna. Las ruinas están, en esta historia, completamente desiertas, y entrañan un peligro misterioso: aquel que se aventura a penetrar en los túneles subterráneos que recorren la ciudad, no regresa jamás. El médico trata en vano de disuadir a Henri de su empeño, pero el escritor no renuncia a su objetivo y, una noche, a la luz de la luna, ambos se encaminan hacia las ruinas. A la entrada de los subterráneos, Henri, tomando el extremo de una cuerda, baja a los túneles, dando instrucciones a su amigo de que si en algún momento tira de la cuerda, será porque está en peligro y él podrá socorrerle. Sin embargo, una vez en el túnel, cuando Henri tira del cordel, el médico se acobarda y es incapaz de acudir en su ayuda. Finalmente, la cuerda se acaba y con ella toda posibilidad de comunicación entre los dos amigos. El médico sale de las ruinas, sufre una enfermedad nerviosa durante días y, finalmente, abandona la ciudad y se traslada a su nueva residencia, donde meses después conoce a Francinette.

La acción de la novela se desarrolla, como ya hemos señalado, en una ciudad denominada C',', formada por la parte nueva de la ciudad correspondiente al puerto y la parte vieja, correspondiente a las ruinas coloniales deshabitadas. Esta disposición nos remite, sin duda, a la del núcleo formado por Lima y su puerto, El Callao, que además había visto por esos años los efectos de la modernización:

El Callao, que sufrió las consecuencias de la guerra con Chile y permaneció ocupado hasta 1883, se recuperó lentamente, al compás de la recuperación de la economía del país. [...] Pero no era sino el suburbio portuario de Lima, apretado contra su fuerte colonial. La ciudad vieja, de calles estrechas e irregular trazado, vio desarrollarse a su lado otra nueva, dibujada en damero, que se extendía hasta La Punta. (Romero, 2004: 252)

Por otro lado, en el artículo "Una publicación notable" (La Opinión Nacional, 16 de diciembre de 1911) Valdelomar reseñaba un trabajo de Carlos Cisneros sobre el departamento de Lima publicado en el Boletín de la Sociedad Geografica. Nos dice Valdelomar:

una de las páginas más ignoradas e interesantes de la antigua Lima de los Virreyes, es la que se refiere a subterráneos, bóvedas, entierros, etc. Todos nosotros hemos oído decir a abuelas, dueñas y viejas criadas negras, de fabulosos y pavorosos subterráneos sobre los cuales se extiende la ciudad de Lima. Hay quienes dicen que la Catedral se comunica con el Palacio, éste con Santo Domingo de donde la red subterránea va a San Agustín y a San Pedro; en fin, que todos los conventos se comunican unos con otros. (Valdelomar, I, 2000: 161-162)

La voluntad de Valdelomar de incorporarse a esas visiones pasatistas de Lima que comentábamos más arriba es más que evidente en esta novela donde, después de introducir la trama principal, Valdelomar hace a su personaje evocar para el viajero Henri D'Herauville la grandeza de la antigua ciudad, evocación tremendamente lírica a la cual dedica varias páginas y que supone una clara distorsión temporal de la acción narrada. En primer lugar, el narrador configura el pasado colonial como un tiempo idílico en el cual la ciudad adquiere el carácter de poderosa y orgullosa:

Estas ciudades, amigo mío, se fueron con la dominación hispana. Estas ciudades netamente españolas no podían vivir la delictuosa época de la República [...]

La independencia, palabra inventada para matar reyes y destruir recuerdos, mató a muchas de esas ciudades coloniales nobles y florecientes. Algunas dejaron que los 
mulatos independizados, los soldados ensoberbecidos, los criollos opulentos, pisotearan sus escudos, hollaran sus blasones y deshojaran sus lises de oro, mas ésta que a nuestros pies duerme el sueño de la muerte, perteneció a las rebeldes, a aquéllas que como Saúl se arrojaron sobre el filo de su espada antes que ver la humillante sonrisa del vencedor. (Valdelomar, II, 2000: 50-51)

La evocación se prolonga durante varias páginas en las que el autor hace contrastar las ruinas con la antigua grandeza de la ciudad. Esta Lima colonial se presenta así poblada de virreyes y damas de corte, cuyas vidas aristocráticas transcurrían entre lujos y placeres. Esta representación nos recuerda las típicas descripciones de los textos modernistas, donde los autores se prodigan en este tipo de recreaciones transidas de lujo y decadencia:

Hay un arco truncado, le decía, donde termina la población. Era el arco triunfal bajo el que entraban a la ciudad sobre ladrillos de plata maciza y hierbas aromosas, los virreyes y su corte, los arzobispos y sus morados familiares. Las damas aristocráticas les arrojaban flores y hacían pender de los barandales de sus balcones tapices finísimos y mantones bordados. Y los trajes. Sedas purísimas, velos transparentes hoy descoloridos por el tiempo, con piedras incrustadas en derroche [...] ¡Gorgueras impecables, mitones de hilos inverosímiles, miriñaques, abanicos de marfil y gasa con amorcillos y mariposas, camafeos que juntaban pliegues sobre hombros de rosa, peinetas monumentales del color de las cabelleras, y sobre todo aquello un par de ojos con visiones de Versalles y un par de labios con sentencias horacianas! (Valdelomar, II, 2000: 54)

Como ya hemos apuntado, esta evocación de la ciudad colonial supone una interrupción de la acción narrada en la carta. En realidad, toda la novela se plantea como un complejo juego donde se superponen varios planos temporales: el lector se enfrenta a una carta escrita en el presente como respuesta a unos acontecimientos sucedidos ocho días atrás, pero donde se relatan hechos que ocurrieron varios años antes y, en pleno relato de aquellos acontecimientos, la acción se ve interrumpida por todo un capítulo dedicado a la evocación de la ciudad colonial, para luego regresar al presente de los hechos narrados en la carta y terminar un relato que es la justificación al abandono de Francinette.

Si Valdelomar hubiera buscado únicamente realizar una evocación de la Lima colonial para instalarse en esa recuperación pasatista de la que hablábamos antes, no hubiera necesitado construir este complejo entramado de acciones y tiempos. Lo que ocurre, como veremos a continuación, es que está disrupción temporal le permite, por un lado, situarse en esa tradición y, por otro lado romperla, en el momento en que en esa evocación activa el tópico europeo de "la ciudad muerta":

$\mathrm{Y}$ en esas noches de luna que hoy ven la ciudad muerta como el cuerpo abandonado de una amante en desgracia ¡cuántas citas de amor tras de las rejas, cuántos caballeros caídos de una estocada, cuántos virreyes disfrazados salvando muros, atravesando frondas de granados en flor y de naranjeros y jazmines para llegar a la ventana entreabierta o a la celosía de una noble Julieta! (Valdelomar, II, 2000: 53)

Recordemos, llegados a este punto, que el tópico europeo de "la ciudad muerta" fue inaugurado por Georges Rodenbach con su novela Bruges-la-Morte (1892). Según Miguel Ángel Lozano, en el artículo "Una visión simbolista del espacio urbano: la ciudad muerta", en las obras que activan este tópico literario, la ciudad se configura como "estado de ánimo" (1994: 61). Para el crítico, este tratamiento de la ciudad es el resultado de la reacción de los autores contra la industrialización que ha modificado 
drásticamente el paisaje urbano durante el siglo XIX. Autores como Rodenbach -que residía en París, capital por excelencia de la modernización decimonónica- recurren al recuerdo de la ciudad de provincia, Brujas en este caso, puesto que "la belleza no está en las modernas y bulliciosas ciudades, sino en aquellas otras periclitadas; aquellas cuya hora ya pasó y muestran la imagen de una hermosa agonía" (Lozano, 1994: 65).

Como explica Lozano, la ciudad no aparece descrita por medio de detalles objetivos, sino meramente sugerida a través de ciertos elementos que configuran el "topos": la ciudad se sitúa al atardecer o de noche, en otoño o invierno, y normalmente con llovizna, calles desiertas o transitadas por tipos muy concretos: ancianas, sacerdotes, etc., las casas permanecen cerradas, predomina el silencio, roto únicamente por las campanadas de las iglesias (1994: 62).

Resulta evidente, si nos atenemos a esta caracterización del tópico y a su dimensión simbólica fundamental, que la ciudad muerta de Valdelomar dista mucho de la sofisticación y profundidad con que autores europeos como Rodenbach habían empleado el espacio urbano como espacio simbólico vehículo para plasmar los estados anímicos de los personajes. Es más, el retrato de una ciudad muerta, efectiva y literalmente muerta, puede llevar a considerar la obra de Valdelomar como fruto de una interpretación algo pueril e ingenua del tópico europeo. Pero sigamos adelante con el análisis.

Hans Hinterhäuser, en su estudio Fin de siglo. Figuras y mitos, dedica un capítulo a estudiar el tópico de las "ciudades muertas" (1998: 41-66), en el cual traza un recorrido por las obras europeas que, en torno al fin de siglo, utilizaron esta noción siguiendo el ejemplo de Rodenbach para dotar a ciudades como Venecia o Toledo de esa dimensión simbólica de la que hablaba Lozano. Empezando su recorrido con la Brujas de Rodenbach, Hinterhäuser asume un criterio más abarcador, incluyendo en su nómina obras como La mort de Venise de Maurice Barrès (publicada en 1903, dentro del volumen Amori et dolori sacrum), Der Tod in Venedig (1912) de Thomas Mann; Greco ou Le secret de Tolède (1912), también de Barrès, Camino de perfección de Pío Baroja o La voluntad de J. Martinez Ruiz "Azorín”, ambas publicadas en 1902 y también ambientadas en Toledo.

Pero además, Hinterhäuser establece tres grupos amplios, el primero de los cuales "abarca evocaciones de ciudades históricas en ruina" (1998: 61-62), dentro del cual está La città morta, el drama que Gabriele D'Annunzio publicó en 1898 y que Lozano descartaba porque el "tratamiento literario de las ruinas, de inspiración arqueológica" (Lozano, 1994: 60) no se ajustaba a su caracterización de la ciudad como estado de ánimo. Valdelomar, admirador declarado de D'Annunzio, toma del drama mencionado el título para su novela y, del mismo modo que las ruinas helénicas embrujan a Leandro, protagonista de La città morta, haciéndole concebir una pasión incestuosa por su hermana, así también las ruinas coloniales subyugan y aniquilan a los personajes de $L a$ ciudad muerta.

Llegados a este punto, resultan particularmente esclarecedoras las palabras de Luis Alberto Sánchez, en torno al "dannunzianismo" que, por los años en que Valdelomar concibe sus novelas, se adueñaba del ambiente cultural limeño:

en Lima estaba entonces de moda el modernismo, que nos llegó con retraso, y el decadentismo, que calzaba con nuestro perenne nirvana y que nos llegó por doble vía: la francesa y la italiana. Campeaba D'Annunzio con sus estilizadas y convencionales evocaciones renacentistas, por lo que Valdelomar no pudo resistir el reto del autor de $I l$ fuoco y de Il piacere, a quien además sentíase atraído por cierto estridente egocentrismo y cierta jactancia histriónica. (1987: 76) 
Podemos entonces situar a Valdelomar en la estela de este dannunzianismo de época. Además, dejando a un lado estas consideraciones de carácter específico, creo que la clave para ver en esta novela de Valdelomar una recreación del tópico europeo nos la da Hinterhäuser, cuando explica el porqué del éxito que dicho tópico obtuvo en la literatura finisecular:

no cabe duda de que en estas ciudades muertas, cualesquiera que sean sus características, se manifiestan dos rasgos fundamentales de la época, rasgos comunes a todos los autores aquí mencionados, por encima de las fronteras nacionales de idiomas y culturas. Nos referimos a la conciencia de decadencia y a la fascinación ejercida por la idea de la muerte. El voluptuoso presentimiento o necesidad de decadencia explica aquella seductora preferencia por lugares en los que ya había tenido lugar tal ocaso, y donde había desaparecido una vida en otro tiempo floreciente; lugares que se adentraban en un presente indigno de ellos, como monumentos en ruina, cargados de melancólicos recuerdos y embellecidos por el arte. (1998: 64)

El ambiente decadente y la fascinación por la idea de la muerte tienen un indiscutible protagonismo en la breve novela de Valdelomar, donde decadencia y muerte se contienen la una a la otra, en tanto que la decadencia manifiesta en las ruinas conlleva, para quien se aventura a las profundidades de la ciudad, la muerte irremediable.

Precisamente como resultado de esa imbricación entre decadencia y muerte, Valdelomar lleva un poco más lejos la complejidad de esta novela, puesto que no se limita a copiar y reproducir un tópico europeo, sino que toma dicho tópico y lo traslada al ámbito peruano, es decir, a la ciudad de Lima, para reescribirlo de una forma innovadora: al dotar a las ruinas de la ciudad de esa dimensión fantasmagórica y misteriosa, la novela entra directamente en las coordenadas de lo fantástico.

En este momento se activa una distorsión espacial, especialmente significativa en la época en que fue escrita la novela. Como ya hemos visto en la cita de Romero, el puerto limeño del Callao se expandía en estos años hacia la ciudad histórica que todavía conservaba su estructura colonial, aunque también comenzaba poco a poco a modernizarse y expandirse. Por estos años también, la alta burguesía y aristocracia limeñas, que tradicionalmente residían en el centro histórico de la ciudad, comenzaron a trasladar su residencia a los "balnearios limeños", a los nuevos barrios que surgían en torno a la ciudad vieja, como Miraflores o Barranco, mientras el centro histórico era ocupado por las clases populares. En su novela, Valdelomar traduce el cese de la vida aristocrática del centro de la ciudad en una ciudad literalmente muerta, abandonada y en ruinas, que embruja a quienes se aventuran en ella y que provoca además la muerte de los que se atreven a bajar a los túneles subterráneos que la recorren. En este espacio de ruinas, la ciudad moderna, escenario del progreso industrial, y la ciudad colonial abandonada y que muere paulatinamente víctima de ese progreso, se funden en un universo fantasmagórico y misterioso que envuelve y enajena a los personajes y que hace que la novela penetre de lleno en el terreno de la literatura fantástica.

Si tenemos en cuenta las categorías de lo fantástico establecidas por los clásicos estudios de Tvetzan Todorov e Irène Bessière, recordaremos que para ambos autores la noción de "ambigüedad" o "incertidumbre" es fundamental. ${ }^{3}$ La ciudad de los muertos

\footnotetext{
3 Todorov estableció una clara diferenciación entre lo fantástico, lo maravilloso y lo extraño. Para él, un relato fantástico es aquel en el que prevalece la "vacilación", es decir, aquel relato en el que el personaje experimenta unos sucesos para los que no encuentra una explicación; tanto el personaje como el lector implícito del relato deben ser incapaces de explicar, al final, si lo que han experimentado/leído ha sucedido en realidad - puede explicarse de forma racional-o contraviene de forma inexplicable las leyes
} 
se ajusta a la perfección a dicha noción puesto que, al finalizar el relato, ni el lector ni el personaje principal son capaces de dar una explicación satisfactoria al misterio de las desapariciones en los subterráneos de la ciudad. Del mismo modo, en ese inexplicable efecto de los subterráneos está funcionando también la noción de lo "sobrenatural" propuesta por el teórico David Roas (2001: 8), puesto que el efecto causado por las ruinas escapa absolutamente a las leyes que organizan el mundo real.

Por otra parte y a pesar de su juventud, Valdelomar demuestra poseer un amplio bagaje de lecturas de la literatura finisecular en boga, tanto hispanoamericana como europea, y ese bagaje le ayuda a pulir la dimensión fantástica de esta novela. En la novela, como bien ha advertido Carlos Eduardo Zavaleta:

hay varias facetas del Valdelomar modernista: la narración poética, el dato escondido sobre la amada enigmática y su revelación progresiva; el otro misterio de la ciudad antigua y fantasmal [...] que devora a quienes se atreven a descender a ese infierno simbólico; los poemas intercalados como refuerzo de la entonación lírica; el género epistolar, sí, pero nunca frívolo como en otros modernistas; y, por fin, las teorías seudocientíficas sobre la locura, los extremos de la mente, las muchas formas en que acecha la muerte, ideas que le acercan a los decadentistas franceses y sobre todo a Edgar Allan Poe, las cuales Valdelomar despliega con exquisita sensibilidad, tanto en descripciones plásticas como el claroscuros psicológicos. (1999: 68)

De entre todos estos rasgos, el que más nos interesa es el último, el referido a esos "claroscuros psicológicos" y a las "teorías pseudocientíficas" que el narrador articula en la novela. Como ya hemos comentado, el protagonista ejerce la profesión de médico y, en un momento de la novela, aventura una complicada explicación para el misterio de las ruinas, explicación que basa en sus conocimientos de las "conexiones cerebrales", título que recibe el capítulo $\mathrm{V}$ de la novela, que está enteramente dedicado a esta curiosa explicación. Cuando Henri pregunta al doctor si de verdad cree científicamente posible que los subterráneos entrañen algún peligro, este responde:

Científicamente es posible [...] esto se explica por medio de las localizaciones cerebrales. $[\ldots]$

Al bajar usted al subterráneo, deja de percibir la influencia de la luz y, como es natural, no habiendo luz que impresione sus ojos, el órgano no funciona y la localización cesa de trabajar, quedando a merced de cualquier acción refleja de las otras; pero al desaparecer la luz el órgano de la orientación se despierta y entra en un período de gran actividad, porque usted cuando se encuentra a obscuras lo primero que hace en el subterráneo es tratar de orientarse. Tiene usted ya, pues, un órgano, el de la vista, inerte, y un órgano, el de la orientación, activo: es decir, una localización, la de la vista, presionada por otra, la de orientarse. Ya este es todo un sistema un sistema casi gráfico. El olfato, al entrar usted al subterráneo, trabaja poderosamente, a consecuencia de los olores especialísimos de ese lugar. Estas vibraciones de la pituitaria se reflejan en su lóbulo correspondiente y presionan al lóbulo inerte de la vista. Hay pues ya dos fuerzas activas actuando sobre una materia en reposo, que por esta influencia pierde su virtud, tal y como pierde su poder atractivo el imán calentado. (Valdelomar, II, 2000: 66-67)

de la naturaleza. El elemento definitorio de lo fantástico para Todorov está esa "vacilación" o "ambigüedad" (2001: 65). Irène Bessière comparte esta idea de "vacilación" o "ambigüedad", con algunos matices y formulada en términos de "incertidumbre": "el relato fantástico une la incertidumbre con la convicción de que un saber es posible: sólo es necesario ser capaz de adquirirlo. El caso existe por la incapacidad del protagonista de resolver la adivinanza" (2001: 100). 
Además, este personaje, que muestra, como es habitual en los héroes finiseculares, debilidad de carácter y voluntad es incapaz de atreverse a bajar a los túneles en busca de su amigo. El narrador se justifica inventando una nueva explicación pseudocientífica para la inestabilidad de sus nervios en el momento de los acontecimientos, provocada, según él, por el influjo que sobre él tiene la ciudad en ruinas y, sobre todo, por el brillo especial de la luna:

La luna, Francinette, tenía ese color verde horrible y sugestionador. Color de alucinación, de fiebre, de sueño de éter. [...] Mas estas luces de la luna no entran por la vista, van más allá, se meten en los nervios, en las fibras, en la sangre, en los huesos. Creo que no obran como color sino como atracción y el color que tenía la luna aquella noche era un color verde metálico que inducía, no me cabe la menor duda, a lo insondable, a lo misterioso, a lo horrible. Entonces yo sentí la necesidad, hasta el deseo, de que Henri bajase y sin decir más le acompañé en silencio. (Valdelomar, II, 2000: 69)

¡Pensaba demasiado! Mi imaginación iba a estallar. Tuve miedo. Miedo de todo, de mí mismo, miedo de cosas invisibles. Dudé un momento todavía y quise bajar pero no tuve bastante valor. Entonces vi de nuevo la luna, verde, verde, verde. [...] Debía ser ya muy tarde y yo, poseído del horror indecible, volteé la cara sin mirar el pozo y regresé, de prisa, apuradísimo, como un criminal, por el centro de las calles y de las plazoletas, temiendo acercarme demasiado a los edificios y atisbando las sobras de éstos que proyectaba la luna. (Valdelomar, II, 2000: 75)

Como plantea Gabriela Mora en su estudio del cuento modernista hispanoamericano, "el deseo de retener el misterio [...] tiene que ver con la actitud hacia la ciencia positivista, el acercamiento al ocultismo, y el asiduo cultivo de la modalidad del género fantástico y sus subtipos" que reflejan la actitud de los modernistas ante la ciencia que "ha perdido su aura al no poder explicar todos los fenómenos" (1996: 21). Esta incapacidad de la ciencia para dar respuesta a los misterios surcará a menudo los textos modernistas.

A este respecto nos dice Luis Alberto Sánchez: "la atmósfera que envuelve la obra resulta irreal, fantasmagórica. Para no serlo tanto, abre el fuego sobre las 'localizaciones cerebrales" (1987: 77-78). Lo expuesto hasta ahora contradice esta afirmación. En mi opinión, Valdelomar no hace proponer a su personaje esa absurda explicación para contrarrestar el elemento fantástico, sino todo lo contrario: ofrece una explicación deliberadamente incapaz de resolver el misterio, dando fuerza así a la dimensión fantástica de la novela.

En definitiva, la complejidad que ya desde el comienzo del capítulo advertíamos en esta obra posibilita a Valdelomar llevar a cabo varias operaciones simultáneas: en su evocación de la Lima colonial se inserta en la tradición literaria peruana, una tradición que intenta renovar de acuerdo con el gusto y la mentalidad de la época y en consonancia con las corrientes literarias europeas del momento, colocándose así -y colocando también a Lima- en la estela cosmopolita propia del modernismo.

Además, como ya hemos apuntado, Valdelomar no se limita a imitar a los autores europeos del momento, sino que logra reescribir el tópico europeo de "la ciudad muerta" de forma original y novedosa por medio de diversas estrategias. En primer lugar, traslada ese tópico al ámbito peruano y a través de la superposición de diferentes planos temporales en la novela, consigue actualizarlo en una tradición literaria diferente. En segundo lugar, conjuga dos espacios narrativos - la ciudad en ruinas y la ciudad nueva- que simbolizan esa tensión de época entre el recuerdo de la grandeza colonial periclitada y el progreso y la modernización que no acaban de llegar. De este modo, con 
La ciudad muerta, Valdelomar configura una imagen inédita de Lima en la tradición literaria peruana.

\section{OBRAS CITADAS}

BASADRE, Jorge (1980): La multitud, la ciudad y el campo en la historia del Perú (con un colofón sobre el país profundo). Lima, Ediciones Treintaitrés y Mosca Azul Editores.

BESSIÈRE, Irène (2001). "El relato fantástico: forma mixta de caso y adivinanza", Teorías de lo fantástico. Ed. David Roas. Madrid, ARCO/LIBROS, 83-106.

HINTERHÄUSER, Hans (1998): "Ciudades muertas", Fin de siglo. Figuras y mitos. Trad. Ma Teresa Martínez. Madrid, Taurus, 41-66.

LOZANO, Miguel Ángel (1994): "Una visión simbolista del espacio urbano: la ciudad muerta", Actas del I Coloquio Internacional "Literatura y espacio urbano". Eds. José Carlos Rovira y José Carlos Navarro. Alicante, Caja de Ahorros del Mediterráneo. Fundación Cultural, 60-73.

MORA, Gabriela (1996): El cuento modernista hispanoamericano. Lima-Berkeley, Latinoamericana editores.

NUÑEZ, Estuardo: "Valdelomar, viajero", Letras, 64 (1960), 58-70.

ROAS, David (2001): "La amenaza de lo fantástico", Teorías de lo fantástico. Madrid, ARCO/LIBROS, 7-46.

ROMERO, José Luis (2004): Latinoamérica: las ciudades y las ideas. Buenos Aires, Siglo Veintiuno Editores.

ROVIRA, José Carlos (2005): Ciudad y literatura en América Latina. Madrid, Editorial Síntesis.

S/A: "Hablando con el Sr. Valdelomar", Barranco, 6 (1996), 138-139.

SÁNCHEZ, Luis Alberto (1987): Valdelomar o la “belle epoque”. Lima, INPROPESA. TODOROV, Tzvetan (2001): "Lo extraño y lo maravilloso", Teorías de lo fantástico. Ed. David Roas. Madrid, ARCO/LIBROS, 65-82.

VALDELOMAR, Abraham (2000): Obras completas. 4 vols. Ed., pról., cron., icon. y notas Ricardo Silva-Santisteban. Lima, Ediciones COPÈ.

VALERO JUAN, Eva: "Evocaciones de la Arcadia Colonial en la literatura peruana: de Ricardo Palma a Julio Ramón Ribeyro", América sin nombre, 5-6 (2004), 230237.

- : "Independencia y romanticismo en el Perú: tentativa, impostura y derrotero", Boletín de la Biblioteca de Menéndez Pelayo, LXXXVI (2010), 253-277.

(2003): Lima en la tradición literaria del Perú. De la leyenda urbana a la disolución del mito. Lleida, Edicions de la Universitat de Lleida.

ZAVALETA, Carlos Eduardo: "La novela poética peruana en el siglo xx", Boletín de la Academia Peruana de la Lengua, 31 (1999), 63-94.

(C) $\mathrm{M}^{\mathrm{a}}$ Elena Martínez-Acacio Alonso

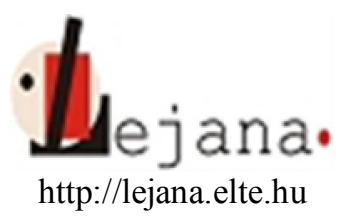

Universidad Eötvös Loránd, Departamento de Español, 1088 Budapest, Múzeum krt. 4/C

Recibido: 16 de febrero de 2015

Aceptado: 13 de octubre de 2015

Ma Elena Martínez-Acacio Alonso: "La metamorfosis de la ciudad literaria: tradición y ruptura..." 